\title{
Urgences
}

\section{Paul Chanel Malenfant, Le siècle inachevé, Rimouski, Éditeq, 1989, 123 p. (avec six dessins de Paul-Émile Saulnier).}

\section{Claude Viel}

Numéro 29, octobre 1990

\section{Éclats d'œuvre}

URI : https://id.erudit.org/iderudit/025615ar

DOI : https://doi.org/10.7202/025615ar

Aller au sommaire du numéro

\section{Éditeur(s)}

Urgences

\section{ISSN}

0226-9554 (imprimé)

1927-3924 (numérique)

Découvrir la revue

Citer ce compte rendu

Viel, C. (1990). Compte rendu de [Paul Chanel Malenfant, Le siècle inachevé, Rimouski, Éditeq, 1989, 123 p. (avec six dessins de Paul-Émile Saulnier).] Urgences, (29), 97-100. https://doi.org/10.7202/025615ar d'utilisation que vous pouvez consulter en ligne.

https://apropos.erudit.org/fr/usagers/politique-dutilisation/ 


\section{Paul Chanel Malenfant, Le siècle inachevé, Rimouski, Editeq, 1989, 123 p. (avec six dessins de Paul-Émile Saulnier).}

Neuvième recueil de Paul Chanel Malenfant, Le siècle inachevé mérite à son auteur le Prix littéraire des Associés 1989, décerné dans le cadre du Salon du livre de Rimouski. Enrichi de six dessins de Paul-Émile Saulnier, le livre comme c'est souvent le cas pour les écrits de Malenfant est divisé en deux parties, presque d'égale longueur cette fois: 1. Choses et 2. Il y a.

L'inversion de la formule *Il y a des choses*, que l'on peut aisément lire dans ces titres, suggère le rebours, l'envers, la déstructuration même. Et c'est exactement ce dont le recueil va parler. Déjà le titre de l'ouvrage soulignait la rupture; sa division en deux parties ne fait que l'exprimer davantage.

Ce livre diffère de tous ceux que le poète a publiés. Auparavant, l'écriture tet le registre familial primaient sur les autres éléments thématiques. Bien qu'il y fasse encore allusion, c'est autour de la mort que Le siècle inachevé gravite, thème auquel Malenfant ne nous avait pas habitués. Et Malenfant en parle avec une franchise, une lucidité parfois intolérables.

Du point de vue formel, le recueil s'éloigne aussi des autres. Bien sûr, les formules jouent encore sur l'ambiguïté - le "je" et le " tu" souvent se confondent, par exemple -, l'absence de ponctuation, à certains endroits, est déroutante, mais l'écriture tend de plus en plus vers la prose, confirmant le mouvement déjà amorcé en ce sens dans Tirer au clair (1988). Cette écriture confêre au texte un caractère davantage intimiste. Le sujet du recueil - la grave maladie d'une femme aimée - imposait au poète un ton différent, rappelant le monologue intérieur. Malenfant s'inspire des propos de l'autre, de souvenirs de voyages ou d'événements du passé pour illustrer combien le présent, devenu si menaçant, est ambivalent, à la fois fragile et impitoyable. Souvent on a l'impression qu'il écrit ce qu'il n'oserait dire et qu'il s'adresse à l'autre en se parlant à lui-même. 
98

Dans chacun des textes, la mort revient, obsédante, et son lent processus nous est révélé. Elle est prise en filature, racontée au quotidien, mot à mot. À cause d'elle, le vide, la peur et la souffrance montent en chacun des membres du couple dont le recueil raconte l'aventure, couple formé du poète et de l'être en sursis qu'il aime.

Deux épigraphes, l'une de Yukio Mishima, * Bref, la mort est l'unique style de la vie * (p. 9), l'autre de Karl Kraus * Seule une langue qui a le cancer incline aux formations nouvelles » (p. 74), débutent respectivement la première et la seconde partie du livre. D'entrée de jeu, elles indiquent au lecteur que la traversée des poèmes ne sera pas facile, que les choses y seront dites telles qu'elles sont, souvent absurdes et déchirantes.

La maladie court d'une page à l'autre. Si dans certains textes, à mots couverts, Malenfant nous la laisse deviner, dans d'autres, elle prend toute la place et l'on connaît son nom: cancer. La terreur de voir grandir ce mal et, surtout, de savoir que cela est inévitable permet au poète d'exploiter à fond le lexique médical. Ainsi les mots qui tuent (chimies, métastases, leucémie, tumeur) se glissent-ils à tour de rôle dans les poèmes et marquent des étapes dans l'évolution de la maladie et de la détresse.

Le corps raconte son effritement: " voici mon corps sur la page " (p. 16). Il a reconnu l'inévitable et « se fait à l'idée * (p. 17), car le mal prolifere: « tu sens la folie des métastases sous la peau et les os * (p. 42). C'est «l'état de guerre [...] parmi les gènes, les molécules " (p. 80). Le code a été changé pour celui de l'autodestruction. Plus de mémoire génétique: "Amnésie, la peau ne pense plus sa forme de peau (p. 45). Peu à peu, le temps s'amenuise: «c'est la fin du siècle parmi les seins et les tumeurs» (p. 82). Le temps fait son œuvre.

Le cerveau n'est plus rempli que d'une seule idée: «lheure de la mort » (p. 58). Cette heure, Malenfant la connaît d'avance, car côtoyer la maladie stimule limagination et, par le fait même, est source de torture: «Jimagine cette heure où on te ferme les yeux et que toute tu passes hors mes mains dans l'invisible lumière d'août" (p. 92). Il ne peut qu'accompagner cette femme vers la mort: « à petit feu vers le noir je m'embarque avec toi », la regarder mourir et constater avec elle que le mal s'accentue: « à petit feu tu désencombres le monde * (p. 39). 
Lorsqu'elle aura franchi la barrière du corps, que restera-t-il d'elle? Où sa voix se répercutera-t-elle? Quelle musique, écrit Malenfant, y a-t-il au-delà du corps? L'oubli trop vite s'installe. Il faut chercher à fixer les images, les souvenirs. Et c'est au pouvoir des mots qu'il fait appel. D'elle la mémoire n'aura bientôt plus d'image précise: “Ce n'est rien. Rien que ta vie en images, dissoutes. Rien que cela ( $p$. 122-123), mais les mots, eux, dans chacune des lettres qui les composent, auront inscrit son souvenir sur du papier, le détachant «de la ligne de mort» (p. 116). En eux, elle continuera à vivre et pourra achever le siècle qu'elle avait commencé.

Il fallait du courage pour écrire ce livre où Malenfant se dévoile ouvertement, où il raconte la difficulté qu'il aura à accompagner l'autre jusqu'au bout: «Tu dis "tu me tiendras la main jusqu'à...": tu verras mes yeux retournés à regarder autre chose * (p. 61). Lorsqu'il écrit « t’aimer à en mourir * (p. 61), il avoue qu'une large part de lui mourra avec l'autre.

Nous le disions plus tôt, Le siècle inachevé s'inscrit mal dans la continuité du travail de Malenfant. À l'époque où ce recueil a été écrit, le poète travaillait à un autre livre, $L a$ table des matières, à paraitre, mais dont on pourra découvrir des extraits dans L'arbre à deux têtes, un essai qui paraîtra au cours de l'automne aux Éditions de l'Hexagone ${ }^{1}$. Malenfant révèle, dans l'entretien qui constitue la seconde partie de l'ouvrage, qu'il veut laisser de côté le registre familial pour aborder de nouveaux thèmes: la pierre, la matière, la voix. De ce point de vue, Le siècle inachevé semblerait donc une sorte de parenthèse insérée dans sa production, l'émotion devenant trop forte pour être contenue. On peut lire dans cet entretien qu'avec La table des matières, il voulait "réfléchir intensément à l'opacité de la pierre, interroger la matière", faire en sorte "que la pensée parvienne à s'exaspérer elle-même d'être confrontée à ce qui ne dit rien, à ce qui, à la limite, n'a aucun sens *. Si l'on réfléchit un instant à l'absurde de la mort, on constate vite que le lien est là entre l'exaspération de la pensée fixée sur ce qui ne dit rien et le silence que le cancer installe. Malenfant dit lui-même qu'on ne peut détacher une œuvre

1 Claude Viel, L'arbre à deux tétes ou la quéte de l'androgyne dans Forges froides de Paul Chanel Malenfant, Montréal, l'Hexagone, 1990. 
100

de son ensemble: * Peut-on vraiment changer sa façon d'écrire? Toutes les étapes d'un projet d'écriture ou d'une pratique d'écriture relèvent d'une continuité. * Confronter pensée et matière, n'est-ce pas essentiellement ce à quoi le cancer contraint?

Claude Viel 